\title{
Perspective
}

\section{The impact of population mobility on dengue fever: an experience from northern Sri Lanka}

\author{
T Kumanan $^{1}$, V Sujanitha ${ }^{1}$, N Rajeshkannan ${ }^{2}$ \\ Sri Lankan Journal of Infectious Diseases 2019 Vol.9 (2):98-102 \\ DOI: http://doi.org/10.4038/sljid.v9i2.8252
}

\begin{abstract}
Dengue infection continues to be a major public health issue and has been a challenge to health authorities for years due to several reasons. It is well known that the virus, mosquito and human factors play significant roles in the transmission of the infection. Traditionally, several preventive measures that are targeted towards the mosquito are well implemented in several countries, including Sri Lanka. Studies have shown that human mobility is a contributing factor in dengue infection and the objective of this report is to give an account on the possibility of human mobility as a major contributing factor for the outbreak of dengue infection in northern Sri Lanka.
\end{abstract}

The gateway "A9" was reopened to the public in mid-2009, as the political unrest had come to a halt by May 2009. Northern Sri Lanka was thereby reconnected with the south, which increased population mobility both ways. An increase in the incidence rate of dengue fever from 10.72 in 2008 to 539.65 in 2010, supported the hypothesis of the possible contribution of human mobility in the dengue outbreak of 2010. Human mobility factors are often overlooked when considering preventive aspects. Preventive measures targeting human movements may enhance effectiveness of dengue control programs.

Key words: Dengue, Human mobility, Northern Sri Lanka, Prevention of dengue

Dengue has been identified as a national problem, causing a huge economic burden to the Sri Lankan health sector in both primary and secondary care over the past two decades. The epidemiology of dengue depends on three key aspects, the dengue virus (DENV) including the four closely related virus serotypes (DEN-1, DEN-2, DEN-3, DEN-4 of Flavivirus genus), the vector (Aedes aegypti) and the human host. Of these, the host factors are often overlooked when considering preventive aspects. However, it is noted that the dengue virus could rapidly spread into new human populations due to human mobility. Studies have shown the role of movement of human population in the spread of dengue infection in several regions of the world. ${ }^{1}$

${ }^{1}$ Department of Medicine, Faculty of Medicine, University of Jaffna, Sri Lanka

${ }^{2}$ Civic Park Medical Centre, NSW 2145, Australia

Address for correspondence: Dr N Rajeshkannan, Civic Park Medical Centre, NSW 2145, Australia

Telephone: +61410008811 Email: kannarohini@gmail.com

(iD) https://orcid.org/0000-0001-9045-3369

Received 5 June 2019 and revised version accepted 22 August 2019 
According to the epidemiological reports of the Ministry of Health, Sri Lanka, the incidence of dengue was minimal in the northern part of Sri Lanka until 2009 with a few sporadic cases reported to the Epidemiology Unit, Ministry of Health as part of routine surveillance (Figure 1). However, as shown in Figure 1, a large outbreak was noted in 2010 followed by a gradual increase in notifications with 4058 notifications being received from the Jaffna district in $2018 .^{2,3}$

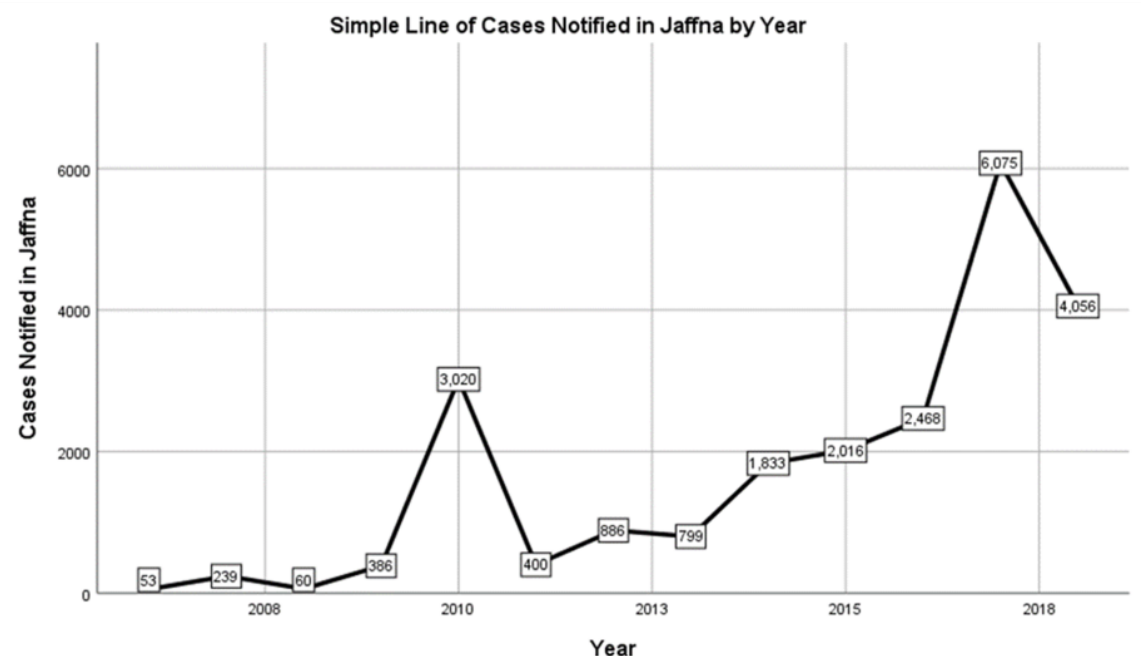

Figure 1: Notification data of dengue cases 2003-2018

Source: Weekly Epidemiological Reports, Epidemiology Unit, Ministry of Health

The land gateway to northern Sri Lanka, popularly known as the "A9" was a strategic point during the three-decade old political unrest and was almost shut down for more than a decade for public transport. The Northern Province (specifically the Jaffna Peninsula) of Sri Lanka was not open to the rest of the island through the land route, though it was geographically connected, owing to the political unrest which prevailed in the region. The A9 was reopened to the public in mid-2009 since the political unrest has come to a halt by May 2009, but traffic between the north and south was minimal initially. Population movement between the south and the Jaffna peninsula increased exponentially in the months following the end of the civil conflict in May 2009 and reached a peak in recent years.

The Jaffna peninsula experienced the highest incidence of dengue and its devastating consequences in the latter part of 2009 and early 2010. From 2008 to 2010, there was a sudden increase in Dengue Fever (DF)/Dengue Haemorrhagic Fever (DHF) in the Jaffna District. A local study reported 58, 422, and 2648 cases of DF in 2008, 2009 and 2010 respectively. ${ }^{3}$ The calculated incidence rate in 2008, 2009 and 2010 was 10.72, 68.98 and 539.65 respectively (Incidence rate calculated per 100,000 by reported dengue cases in years 2008 (60), 2009 (386) and 2010 (3020) divided by 2007 mid-year population). Movement of people in both directions could have contributed significantly to the increase in number of DF/DHF cases following the reopening of the "A9" highway. Even though some may argue that underreporting may explain the low numbers reported prior to 2008, the increase of more than 2000 cases in 2010 cannot be explained by underreporting and one important reason could be the increased human mobility of the region. 
Dengue is endemic in northern Sri Lanka since then, although seasonal variations exist. There was clear evidence that the vector mosquito Aedes was present in the northern region for a long time as shown by the epidemic of Chikungunya in the Northern Province in 2006/2007. ${ }^{4}$ It is therefore most likely that the low incidence of DF/DHF prior to 2009 was due to the low level of the DENV in Jaffna prior to this period. It is a well-known fact that the adult Aedes aegypti can only fly short distances, on average 400 meters. This suggests that the introduction of the dengue virus into the Jaffna peninsula, allowed rapid carriage of the dengue virus due to the movement of the human population. ${ }^{5}$

A meta-analysis in India showed low co-circulation of multiple dengue virus serotypes as possible contributors of outbreaks and endemic dengue. ${ }^{6}$ In 2017, Sri Lanka experienced an outbreak of dengue infection which was extensively studied and the emergence of a new strain, DEN-2, was identified as a possible contributing factor. ${ }^{7}$ However the study did not explore human mobility as a factor for possible contribution to the outbreak which happened in the Northern Province. Due to the absence of serological studies in the Northern Province, comparison could not be made with serological studies in other part of the country such as the Western Province.

A study reported from Vietnam found that a very narrow range of critical human population densities between 3,000 to 7,000 people $/ \mathrm{km}^{2}$ were prone to dengue outbreaks. ${ }^{8}$ Research done in Taiwan and Puerto Rico showed that the spatial distribution of dengue incidence may be positively related to the population density. ${ }^{9,10}$ Population density indicates how many people live in a defined geographical area. Generally, population density is reported in square kilometres/miles. The area of Jaffna district is $1,025 \mathrm{~km}^{2}$ with a population density of

Table1: Jaffna population over the decades

\begin{tabular}{|c|c|c|c|c|c|c|}
\hline Name & Status & $\begin{array}{c}\text { Population } \\
\text { Census } \\
\text { 1981-03-17 }\end{array}$ & $\begin{array}{l}\text { Population } \\
\text { Census } \\
2001-07-17\end{array}$ & $\begin{array}{c}\text { Population } \\
\text { Special } \\
\text { Enumeration } \\
2007\end{array}$ & $\begin{array}{l}\text { Population } \\
\text { Census } \\
2012-03-20\end{array}$ & $\begin{array}{c}\text { Population } \\
\text { Estimate } \\
2018-07-01\end{array}$ \\
\hline \multirow[t]{2}{*}{ Jaffna } & \multirow[t]{2}{*}{ District } & \multirow[t]{2}{*}{738,788} & \multirow[t]{2}{*}{490,621} & 559,619 & 583,882 & 613,000 \\
\hline & & & & \multicolumn{3}{|c|}{ Increase of $24,263 \quad$ Increase of 29,118} \\
\hline
\end{tabular}

Source: Department of Census and Statistics, Sri Lanka (web).

Explanation: All 2018 estimates are provisional

$598.0 / \mathrm{km}^{2}$ in 2018 with a change of $+0.78 \% /$ year from 2012 to $2018^{11,12}$. Epidemiologists are well aware of the negative effect of a high population density on historical epidemics like measles, influenza and dengue. An increase in the population of 24,263 from 2007 to 2012 and 29,118 from 2012 to 2018 (Table 1) can be correlated with the outbreaks in 2010 and 2017 respectively (peaks as shown in Figure 1). 
A study done recently in Pakistan pointed out that mobility estimates calculated based on mobile phone application can be used to predict geographic spread and timing of emerging locations. ${ }^{13}$ The researchers have combined transmission suitability maps with estimates of seasonal dengue virus importation to generate fine-scale dynamic risk maps with direct application to dengue containment and epidemic preparedness. ${ }^{10,14}$ This fact is further emphasized by a study in Thailand which concluded that understanding of human movement at the local level may be helpful for planning of dengue prevention activities. ${ }^{15}$

As discussed above, we postulate that human mobility contributed to the outbreak of DF/DHF in 2010 and suggest that a country with endemic dengue should consider human mobility as an important epidemiological aspect in the investigation of dengue outbreaks. It is therefore an important consideration when drawing up prevention, surveillance, and preparedness strategies to combat not only DF but all vector borne viral diseases. We conclude that rigorous studies on the role of human movement by using different scales will significantly help in the understanding of DENV transmission, which is critical to further improve the effectiveness of prevention programs.

\section{References}

1. Stoddard ST, Forshey BM, Morrison AC, et al. House-to-house human movement drives dengue virus transmission. Proc Natl Acad Sci U S A. 2013; 110(3):994-9.

doi: https://doi.org/10.1073/pnas.1213349110

2. Epidemiology Unit, Ministry of Health, Weekly Epidemiological Reports, available at: http://www.epid.gov.lk/web/index.php? option $=$ com_content\&view $=$ article\&id $=148 \&$ Itemid $=449$ \&lang=en accessed on 14.07.2019

3. Murugananthan K, Kandasamy M, Rajeshkannan N, et al. Demographic and clinical features of suspected dengue and dengue haemorrhagic fever in the Northern Province of Sri Lanka, a region afflicted by an internal conflict for more than 30 years - a retrospective analysis International Journal of Infectious Diseases. 2014; 27,e32-e36 doi: https://doi.org/10.1016/j.ijid.2014.04.014

4. Surendran, S \& Kannathasan, Kajatheepan, A, et.al. Chikungunya-type fever outbreak: some aspects related to this new epidemic in Jaffna district, northern Sri Lanka. Tropical Medicine and Health. 2007; 35:249-252. doi: https://doi.org/10.2149/tmh.35.249

5. WHO, Dengue control, The Mosquito, available at: https://www.who.int/denguecontrol/mosquito/en/ accessed on 01/06/2019

6. Ganeshkumar P, Murhekar MV, Poornima V, et al. Dengue infection in India: A systematic review and metanalysis. PLoS Negl Trop Dis 2018; 12(7):e0006618. doi: https://doi.org/10.1371/journal.pntd.0006618

7. Ali S, Khan AW, Andrew WT, et.al. The unprecedented magnitude of the 2017 dengue outbreak in Sri Lanka provides lessons for future mosquito-borne infection control and prevention Infection, Disease \& Health .2018; 23:114e120 doi: https://doi.org/10.1016/j.idh.2018.02.004

8. Schmidt W-P, Suzuki M, Dinh TV, et al. Population density, water supply, and the risk of dengue fever in Vietnam: cohort study and spatial analysis. PLoS Med. 2011; 8(8):e1001082. doi: https://doi.org/10.1371/journal.pmed.1001082

9. Ko, Y.C. Epidemiology of dengue fever in Taiwan. Kaohsiung J. Med. Sci. 1989; 5:1-11. 17. PMID: 2659810

10. Morrison A.C, Getis A, Santiago M, et.al. Exploratory space-time analysis of reported dengue cases during an outbreak in Florida, Puerto Rico, 1991-1992. Am. J. Trop. Med. Hyg. 1998; 58:287-298. PMID: 9546405 
11. Department of Census and statistics, Basic Population information on Jaffna District, 2007. Available at:

www.statistics.gov.lk/PopHouSat/Preliminary\%20Reports\%20Special\%20Enumeration\%202007/ Basic\%20Population\%20Information\%20on\%20Jaffna\%20District\%202007.pdf_accessed on $14 / 07 / 2019$

12. Jaffna (District, Sri Lanka) - Population Statistics - City Population available at: https://www.citypopulation.de/php/srilanka-prov-admin.php?adm2id=41 Accessed on 14/07/2019

13. Wesolowski A, Qureshi T, Boni MF, et al. Impact of human mobility on the emergence of dengue epidemics in Pakistan. Proc Natl Acad Sci U S A. 2015; 112(38):11887-92. doi: https://doi.org/10.1073/pnas.1504964112

14. Stoddard ST, Morrison AC, Vazquez-Prokopec GM, et.al. The role of human movement in the transmission of vector-borne pathogens. PLoS Negl Trop Dis. 2009; 3(7):e481. doi: https://doi.org/10.1371/journal.pntd.0000481

15. Houa, CYP. Kittayapongb J, Mumforda, LR, et.al. Dengue transmission through human movement in regular and seasonal patterns on Koh Chang Island in Thailand, International Journal of infectious disease, 2016; 53(S):95. doi: https://doi.org/10.1016/j.ijid.2016.11.239 